\title{
QUADRUPLE SYMMETRIC REAL SIGNALS SPECTRAL EVEN AND ODD DECOMPOSITION
}

\section{SPEKTRALNA DEKOMPOZICIJA ČETVOROSTRUKO SIMETRIČNIH REALNIH SIGNALA PARNIM I NEPARNIM DELOVIMA SIGNALA}

Venelin JIVKOV

Philip PHILIPOFF
ORIGINALNI NAUČNI RAD ORIGINAL SCIENTIFIC PAPER

UDK: 517.9

517.518 .45

doi: $10.5937 / g r m k 1603063 \mathrm{~J}$

\section{INTRODUCTION}

Spectral even and odd decomposition of quadruple symmetric real signals is illustrated in the case of:

\subsection{SH (polarized in horizontal plane) wave} propagation through multi layered media $[1,2,3,4,7]$

The wave propagation process, at the direction of the axis $x$ perpendicular to the investigated multilayered media (fig. 1), could be described by the following equation:

The wave propagation process, at the direction of the axis $x$ perpendicular to the investigated multilayered media (fig. 1), could be described by the following equation:

$$
\frac{\partial^{2} W\left(x_{r} t\right)}{\partial t^{2}}-V_{3 H} \frac{\partial^{2} W\left(x_{r} t\right)}{\partial x^{2}}=0
$$

where $\quad V_{S H E}=\sqrt{\frac{E}{\rho}} \quad$ is the wave propagation velocity for the shear waves $\mathrm{SH}, \mu=$ const is the Lame coefficient, $\rho=$ constant represents mass density. The function $w(x, t)$ is the anti plane $(X, Y)$ component of the displacement vector in the direction parallel to the axis $Z$.

On the boundary between the two neighbouring layers " $i$ " and " $i+1$ " the corresponding boundary conditions are satisfied. These boundary conditions represent that the unknown displacements and forces (stresses) are continuous:

$$
w\left(x_{1}+\right)_{\text {boundary }}=w(x, t) \text { boundary }
$$

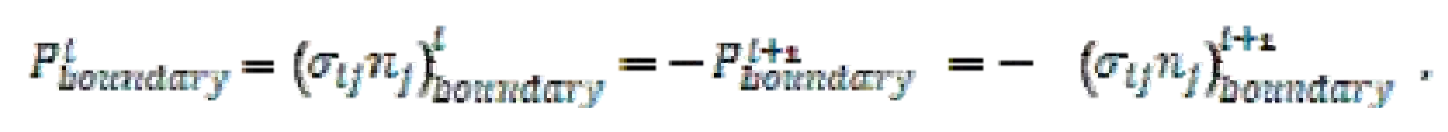

Philip Philipoff, Assistant Professor, PhD, Institute of Mechanics-BAS, acad.G.Bonchev street, 4 bl., phone: +359 8882811 75, e-mail: philip.philipoff@gmail.com; philip_philipoff@imbm.bas.bg

Venelin Jivkov, Corresponding Member of BAS, Professor, Senior Doctor of Sciences, Technical University-Sofia, 8 Kliment Ohridsky boulevard, phone: +359 888658181 , e-mail: jivkov@tu-sofia.bg where $\mathrm{P}^{\mathrm{i}}$ is the boundary force vector of the corresponding layer, $\sigma_{i j}$ is the stress tensor, and $n_{j}$ is the corresponding normal vector. The initial conditions with respect to the displacement and to the first difference are homogeneous. The both functions depend on the spatial variable $x$ and time argument $t$ in the initial moment $t=0$ : 


$$
\left.w x_{0} t\right|_{t=0}=0,\left.\quad \frac{\partial w 0 \cdot t}{\partial t}\right|_{t=0}=0
$$

For the direct problem [1, 2, 3, 4] on the bedrock the displacement boundary condition is given in the mode of the known time function:

$$
w(0, t)=X_{b}(t) .
$$

The free surface stresses (force boundary conditions) are homogeneous for the investigated direct and inverse problems $[1,2,3,4]$ :

$$
P^{\text {surface }}=\left(\sigma_{l y} n_{l}\right)^{\text {surface }}=0 .
$$

On the other hand, for the inverse problem $[1,2,3,4]$ on the free surface, the displacement boundary condition is given in the mode of the known time function:

$$
w(l, t)=X_{s}(t)
$$

\subsection{Structural mathematical model of the multi layered structure.}

The structural model of the multilayer media is shown in fig. 1. The SH Wave Propagation Reflect - Pass Perpendicular Process is illustrated on the fig.1 a. The Block - Diagram Model of the media under investigation is shown in fig.1 b. The Flow Graph of the system signals is shown in the fig.1. $c$.

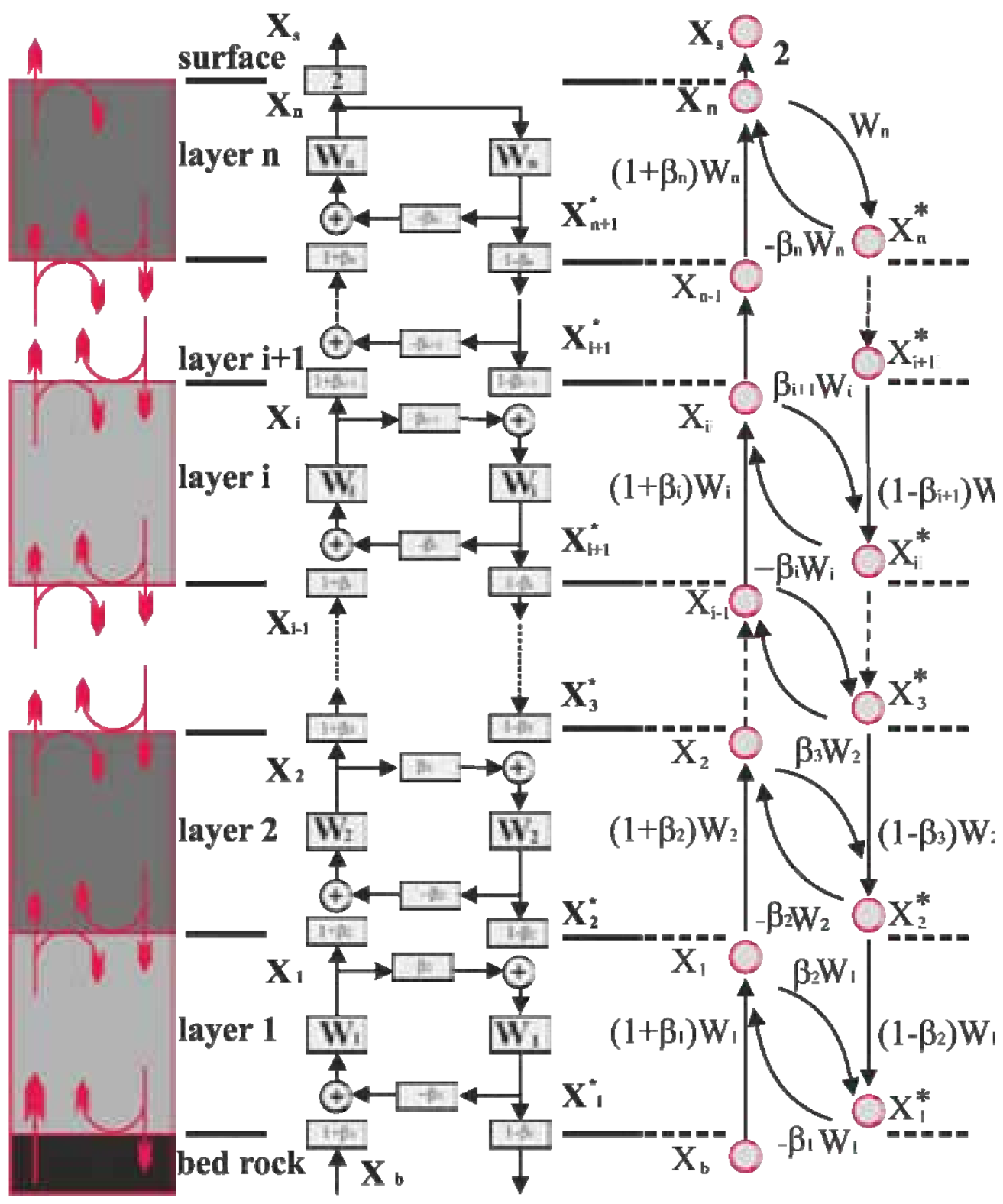

a)

b)

c)

Fig. 1. Multilayered Media Structural Model. a) SH Wave Propagation Reflect-Pass Perpendicular Process. b) Block Diagram Model. c) Signal Flow Graph. 
The above formulated SH wave boundary condition problem (1) - (7) could be solved by a system of differential equations, initial and boundary conditions. This differential system consists of the following elements $[1,2,3,4]$ :

- $n$ equations in the mode (1), one differential equation for each layer, because the velocity function

\section{$V(x)$}

depending on spatial co-ordinate $x$ is discontinued and is a terrace-like type;

- 2( $n-1)$ boundary conditions in the mode (2), (3);

- surface boundary condition in the mode (6);

- initial conditions in the mode (4),

- and either of boundary conditions (cinematic excitation) (5) for the direct problem or (7) for the inverse problem.

The above formulated wave boundary problem (1)(7) can be transformed in the complex domain. The solution of the investigated problem (1)-(7) in the complex domain could be obtained by solving the following algebraic system of equations $[1,2,3,4]$ :

$$
\begin{aligned}
& X_{1}(s)=W_{i}(s)\left[\left(1+\beta_{1}(s)\right) X_{b}(s)-\beta_{1}(s) X_{1}^{*}(s)\right], \\
& * * * * * * * * * \\
& X_{i}(s)=W_{i}(s)\left[\left(1+\beta_{i}(s)\right) X_{i-1}(s)-\beta_{i}(s) X_{i}^{*}(s)\right], \\
& * * * \quad * * * \quad * * * \\
& X_{i}^{*}(s)=W_{i}(s)\left[\beta_{i+1}(s) X_{i}(s)+\left(1-\beta_{i+1}(s)\right) X_{i+1}^{*}(s)\right], \\
& * * * \quad * * * \quad * * * \\
& X_{n}^{*}(s)=W_{n}(s) \quad X_{n}(s) .
\end{aligned}
$$

The unknown variables in the system (8) (X1 $\left.X_{2}, \ldots, X_{i}, \ldots X_{n}, \quad X_{1}^{*}, \quad X_{2}^{*}, \ldots, X_{i}^{*}, \ldots, X_{n}^{*}\right)$ represent the displacements, velocities or accelerations of the media particles under investigation. The coefficients $\beta=\beta(s)=$ $\operatorname{Re} \beta$ (s) $+\mathrm{j} \operatorname{Im} \beta$ (s) in the system (8) are reflection and refraction layer ratios (see fig. $1 \mathrm{~b}$, fig. $1 \mathrm{c}$ ). They are known complex functions of the parameter of integral transformation.

\subsection{Transfer function of the multi layered structure.}

The connections between the signals in the algebraic system (8) could be visualized by the oriented graph. Similar oriented graph is shown in the fig.1.c. This mathematical description represents a system of $2 n$ algebraic equations. The system of variables, the seismic signals on the both sizes of each layer boundary $\left(X_{1}, X_{2}, \ldots, X_{i}, \ldots X_{n}, X^{*}{ }_{1}, X_{2}^{*}, \ldots, X_{i}^{*}, \ldots, X_{n}^{*}\right)$, and the system of coefficients, reflection and refraction layer ratios, are complex-valued. This choice of the system of variables approximates the investigated structural model to the corresponding continuous differential problem. The variables in the above mentioned system (8) ( $X_{1}$, $\left.X_{2}, \ldots, X_{i}, \ldots X_{n}, X_{1}^{*}, X_{2}^{*}, \ldots, X_{i}^{*}, \ldots, X_{n}^{*}\right)$ for the continuous and discrete problems are identical. The equation (7) together with the used integral transformation of the initial boundary value problem [1, 2, 3, 4] affords the opportunity to solve direct and inverse problem of the engineering seismology $[1,2,3,4]$ in the complex domain. In this system the differential equation (1) takes part only indirectly by the corresponding transfer function of the problem. The function matrix of the system (8) is asymmetric. Based on this fact, the common transfer function of the problem $\psi(B)$ could be obtained by recurrent elimination of the system parameters. This function physically represents the quotient between images of input and output signals of the geological structure under investigation $[1,2,3,4]$ :

$$
\Psi(\mathbf{s})=\left\{\mathbf{X}_{\text {input }}(\mathbf{s})\right\}^{-1}\left\{\mathbf{X}_{\text {output }}(\mathbf{s})\right\} .
$$

Substituting the analytical complex parameter "s" by the numerical imaginary parameter " $j \omega$ " into system of equations (8), it is possible to calculate numerically the formulated direct and inverse problems [1, 2, 3, 4] by means of Fourier integral transformation.

\section{QUADRUPLE SYMMETRIC REAL FUNCTIONS.}

The coefficients $\beta=\beta(j \omega)=\operatorname{Re} \beta(\Phi)+j \operatorname{Im} \beta(\Phi)$ in the system (8) are reflection and refraction layer ratios according to the Willebrord Snellius (1580-1626) low (see fig. $1 \mathrm{~b}$, fig. $1 \mathrm{c}$ ). They are known complex functions of the frequency $\boldsymbol{\omega}$. The properties of the layers under investigation of structural model in fig.1 [ 7, 8 ] are presented in mathematical description (8) by corresponding layer transfer function signed

$W_{i}(j \varpi)$ and corresponding reflection and refraction coefficients signed $\beta_{i}(j \omega)$. By suitable selection of the real and imaginary parts of the coefficients $\beta_{i}(j \Phi)$ can be obtained quadruple symmetric real functions presented in the first quadrant of the fig. 2 in a capacity of searched problem solution. In the case of real and imaginary parts of the coefficients $\beta_{i}$ according to the conditions of Theorem 1 of the present paper, the signal will be received in the second quadrant. In the case of real and imaginary parts of the coefficients $\beta_{i}$ according to the conditions of Theorem 3 of the present paper, the signal will be received in the third quadrant. The signals from third quadrant and from fourth quadrant can be obtained also in the case of real and imaginary parts of the coefficients $\beta_{i}$ according to the conditions of Theorems 2 and 4 of the present paper respectively.

The five theorems (they are published as sub conditions in the theorem 2.1 in [5] signed by * and here points) describe the Symmetry - Conjugation relation:

- Theorem 1 (The phenomenon "Symmetry" in the time domain corresponds to the phenomenon "Conjugation" in the frequency domain). The complex Fourier $F(j \omega)$ spectra of the symmetric real functions in the first and second quadrants are conjugated as well as.

- Theorem 2. The complex Fourier $F(j \omega)$ spectra of the symmetric real functions in the third and fourth quadrants are conjugated respectively.

- Theorem 3 (The phenomenon "Anti Symmetry" in the time domain corresponds to the phenomenon "Anti Conjugation" in the frequency domain). The complex Fourier $F(j \omega)$ spectra of the anti symmetric real functions in the first and third quadrant are anti conjugated as well as. 


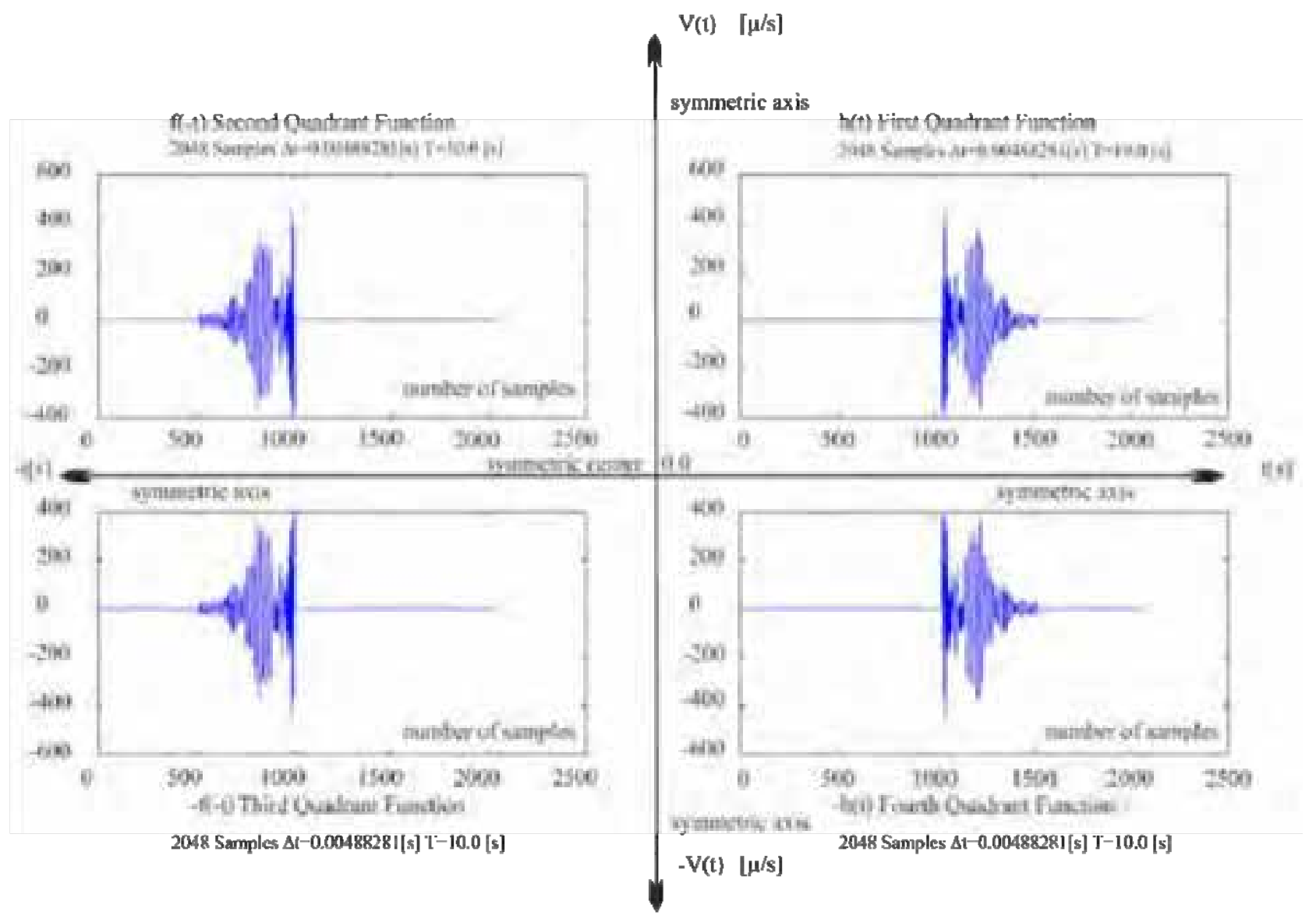

Fig. 2. Quadruple symmetric real functions for the velocities media particles $V(t)[\mu / s]$ from fig.1.

- Theorem 4. The amplitudes of functions in the first and second quadrants are both positive, while the amplitudes of functions in the third and four quadrants are both negative. The functions under investigation could be of arbitrary amplitudes - negative or positive. The corresponding complex Fourier $F(j \omega)$ spectra are also of arbitrary type amplitudes - negative or positive.

- Theorem 5 (Frequency indistinguishable). Four quadruple symmetric real functions are frequency indistinguishable.

\section{FOURIER TRANSFORMABLE FUNCTIONS.}

The well known Dirichlet conditions are sufficient for function $f(t)$ in the time domain to be Fourier transformable [6] pp-73. It follows:
3.1 The function $f(t)$ is limited in the absolute value mode:

$$
\int_{-\infty}^{\infty}|f(t)| d t<\infty
$$

3.2 $f(t)$ has finite maxima and minima within any finite interval.

3.3 $f(t)$ has a finite number of discontinuities within any finite interval.

The direct and inverse Fourier transformations are given by:

$$
\begin{aligned}
& F(j \omega)=\int_{\infty}^{\infty} f(t) e^{-l \omega t} d t ; \\
& f(t)-\frac{1}{2 \pi} \int_{\infty}^{\infty} F(\omega) e^{f \omega t} d \theta .
\end{aligned}
$$




\section{ODD AND EVEN REPRESENTATIONS.}

It is well known that any function in the time domain can be decomposed into an odd and even function [6] pp-75 as follows:

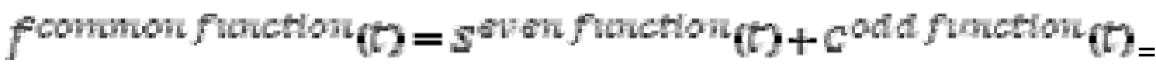

$$
\begin{aligned}
& \frac{f \text { common funstion(t) fcommon funching } t)}{2}+ \\
& +\frac{f^{\text {conmon function }}(t)+f^{\text {conmon fuchation }}(-t)}{2} .
\end{aligned}
$$

Theorem 6 (The phenomenon "Symmetry" in the time domain corresponds to the phenomenon "Conjugation" in the frequency domain. The phenomenon "Anti Symmetry" in the time domain corresponds to the phenomenon "Anti Conjugation" in the frequency domain. The simultaneous operation of the Theorems 1 and 3 leads to even and odd decomposition of the Fourier complex spectrum of the common function with length $\mathrm{N}$ in the time domain. This result represents spectral function, composed by the equivalent nonzero real and imaginary spectral parts with length $N / 2$ in the frequency domain).

Any real common function in the time domain can be decomposed in a symmetric and anti symmetric components. The Fourier spectrum of the common function:

$$
\text { F comman function }(j \omega)-\frac{1}{\sqrt{2 \pi}} \int_{-w}^{+\infty} \text { fcammon function }(t) e^{-l \omega t} d t,
$$

can be obtained by adding twice real left part $R_{\text {venleft }}(\omega)$ of the symmetric component Sovenfunction (f) :

$$
\begin{aligned}
& \text { Seven function }(j k)=\frac{1}{\sqrt{2 \pi}} \int_{-\infty}^{+\infty} \text { seven function }(t) \rho^{-i \omega t} d t=
\end{aligned}
$$

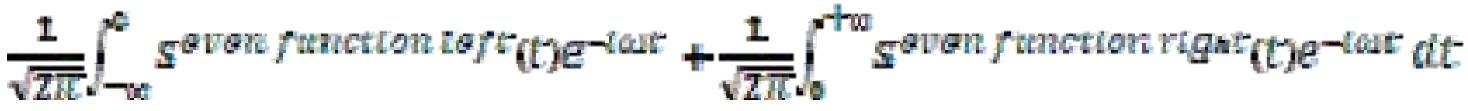

plus imaginary unit "j" multiply by twice imaginary right

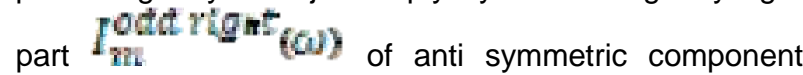
Codt function (t):

$$
\begin{aligned}
& \text { Codt function }(j \omega)=\frac{I}{\sqrt{2 \pi}} \int_{w}^{+w} c^{o d t} \text { functioni }(t) e^{-l o u t} d t=
\end{aligned}
$$

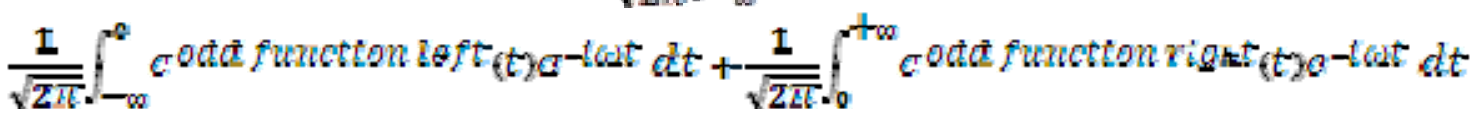

because of linearity of the above mentioned integrals in (14) and (15) and using the popular rule for zero integral from zero integrand function [9]. Than the complex spectra of the common function could be obtained by the following relation:

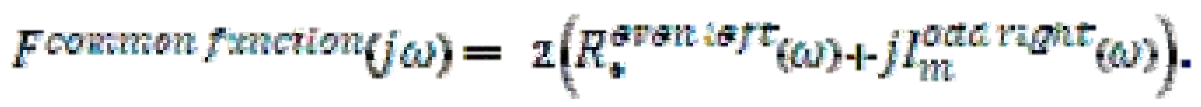




\section{Proof of the Theorem 6.}

$$
\begin{aligned}
& \text { The Fourier complex spectrum } \\
& \text { Sevenfunction }(j \mathrm{i}) \text { ) of the symmetric }
\end{aligned}
$$

component seven function $(t) \overline{\bar{L}}$ of the common function fcomizion function $(t)$ rI can be written as follows:

$$
\begin{gathered}
\text { Seven function }(j \omega)=\frac{1}{\sqrt{2 \pi}} \int_{-w}^{\text {twe }} \text { seven function }(t) \theta^{-i \omega t} d t= \\
R_{*}^{l e f t}(\omega)+j I_{m}^{l e f t}(\omega)+-R_{*}^{r i g t}(\omega)+j I_{m}^{r i g n t}(\omega) .
\end{gathered}
$$

Symmetric component could be decomposed as follows:

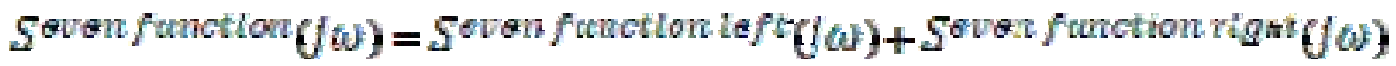

$$
\begin{aligned}
& \text { Sovan function lsft }(j \omega)=R_{\psi}^{l \theta f t}(\omega)+j I_{n i}^{L S T}(\omega)
\end{aligned}
$$

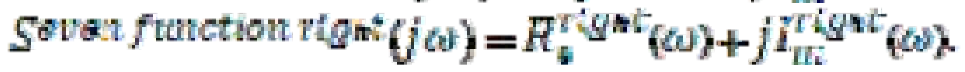

According to (10) from [5] pp-346 for the symmetric function left Sovon fumction left $(j \omega)$ and for the symmetric function right

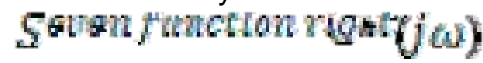

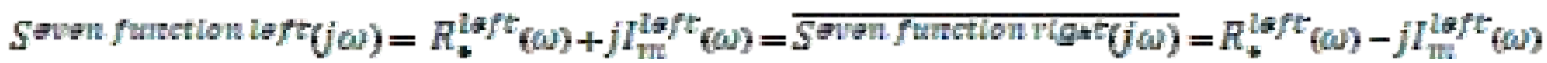

$$
\begin{aligned}
& \text { Seven functian }(j \omega)=S \text { aven function left }(j \omega)+S \text { even function } r i g a t(j \omega)= \\
& R_{*}^{l e f t}(\omega)+j I_{m}^{l e f t}(\omega)+R_{t}^{l e f t}(\omega)-j I_{m}^{l e f t}(\omega)=2 R_{*}^{l e f t}(\omega)
\end{aligned}
$$

The Fourier complex spectrum codtefunction $(j \omega)$ of the anti symmetric component codd function $(\mathrm{t})$ of the common function

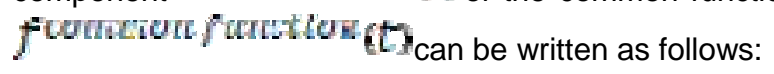

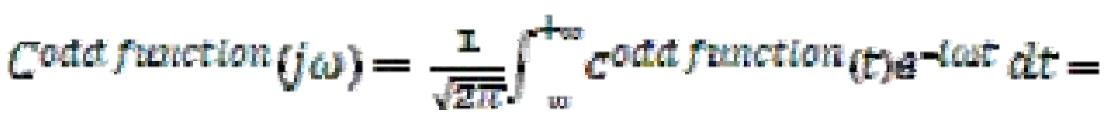

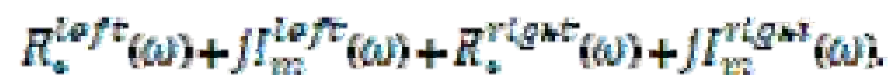

Anti symmetric component could be decomposed as follows:

$$
\begin{aligned}
& \text { Codt function }(j \omega)=\text { Codd function left }(j \omega)+\text { Codt functian right }(j \omega) \\
& \text { Codd function left }(\omega \omega)=R_{v}^{i \theta f t}(\omega)+J I_{m}^{i \theta f t}(\omega) \\
& \text { Codt function rigns }(j \omega)=R^{r i g h t}(\omega)+j I_{m i}^{r i g t t}(\omega) \text {. }
\end{aligned}
$$


According to (10) from [5] pp-346 for the symmetric function left codef function left $(j \omega)$ and for the symmetric function right coctet function $\operatorname{rtgn}(j \omega)$ :

$$
\text { Codd function laft }(j \omega)=R_{v}^{l a f t}(\omega)+j I_{m}^{l e f t}(\omega)=\overline{\text { Codd function righ }(j \omega)}=-R_{v}^{l e f t}(\omega)+j I_{1 \omega}^{l e f t}(\omega)
$$

$$
\begin{aligned}
& \text { Codt function }(j \omega)=\text { Codt function left }(j \omega)+\text { Codt function rigat }(j \omega)= \\
& R_{v}^{r l g h t}(\omega)+j I_{n}^{r l g h t}(\omega)-R_{v}^{r l g h t}(\omega)+j I_{m}^{r i g h t}(\omega)=2 j I_{m}^{r l g h t}(\omega)
\end{aligned}
$$

Finally:

$$
\text { Fconmon function }(j \omega)=\mathbf{z}\left(R_{v}^{\text {even laft }}(\omega)+j T_{m i}^{\text {odtc } r i g h t}(\omega)\right) \text {. }
$$

\section{ILLUSTRATIVE NUMERICAL EXAMPLES.}

The proof of the Theorem 6 is presented analytically in the paragraph four of the present paper. This proof of the Theorem 6 can be illustrated by the following eight numerical examples. The first example represents common real function of discrete type. The next eight numerical examples are of symmetric or anti symmetric discrete type functions. All examples illustrated the process of even and odd decomposition numerically.

\subsection{First Common Function Numerical Example: "Rectangular Half Wave".}

Three figures number 3, 4 and 5, show the process of decomposition of common function "Rectangular Half Wave" by eight samples. Figure 3 illustrates decomposition of common function in even and odd components according to [6]. Figure 4 illustrates decomposition of even component in a "Symmetric Wave Component Left" and "Symmetric Wave Component Right" according to relation (17). Figure 5 illustrates decomposition of odd component to "Anti Symmetric Wave Component Left" and "Anti Symmetric Wave Component Right" functions according to relation (23).

Table 1 and Table 2 illustrate the possibility of calculating complex Fourier spectra of the "Rectangular Half Wave" by the relation (28). The initial common function is shown in the row 2 of Table 1 . The row 4 of Table 1 shows symmetric component of the initial function and the row 6 of Table 1 shows anti symmetric component of the initial function. The "Even Left Function" from the Theorem 6 is shown in the row 9 of Table 1. The "Odd Right Function" from the Theorem 6 is shown in the row 11 of Table 1.

The coefficients of the complex Fourier spectra of the "Rectangular Half Wave" are shown in the row 14 of Table 1. They are obtained by the function "fft" of MatLab program system [10]. The "Complex coefficients of the $1 / 2$ event left component of the rectangular half wave" are shown in the row 16 of Table 1. The "Complex coefficients of the $1 / 2$ odd right component of the rectangular half wave" are shown in row 18 of Table 1. The "Complex coefficients of the $1 / 2$ event left component
+ Complex coefficients of the $1 / 2$ odd right component of the rectangular half wave" are shown in the row 20 of Table 1. The "Complex coefficients of the $1 / 2$ event left component - Complex coefficients of the $1 / 2$ odd right component of the rectangular half wave" are shown in the row 22 of Table 1. Finally, the "\{Complex coefficients of the $1 / 2$ event left component + Complex coefficients of the $1 / 2$ odd right component of the rectangular half wave $\}$ + \{Complex coefficients of the $1 / 2$ event left component Complex coefficients of the $1 / 2$ odd right component of the rectangular half wave \}" are shown in the last row 24 of Table 1 . This operation closed the illustration of applying the relation (28) for the numerical example under consideration. The row 24 of Table 1 is identical of the row 14 of Table 1 . This is the numerical proof of the numerical example "Rectangular Half Wave". This numerical proof shows, that the complex Fourier spectra calculated by MatLab program system [10] directly and complex Fourier spectra calculated by using the relation (28) are identical.

In addition, Table 2 showing the numerical example under investigation has illustrated the inverse composition of the initial "Rectangular Half Wave". The "Complex coefficients of the $1 / 2$ event left component of the rectangular half wave" are shown in the row 27 of Table 2. The "Inverse Samples of the $1 / 2$ event left component of the rectangular half wave - Time Domain" are shown in the row 29 of Table 2. The "Complex coefficients of the $1 / 2$ odd right component of the rectangular half wave" are shown in the row 32 of Table 2. The "Inverse Samples of the $1 / 2$ odd right component of the rectangular half wave - Time Domain" are shown in the row 34 of Table 2. The "Complex coefficients of the $1 / 2$ event left component + Complex coefficients of the $1 / 2$ odd right component of the rectangular half wave" are shown in the row 37 of Table 2. The "Inverse Samples of the Complex coefficients of the $1 / 2$ event left component + Complex coefficients of the $1 / 2$ odd right component of the rectangular half wave - Time Domain" are shown in the row 39 of Table 2. The "Complex coefficients of the $1 / 2$ event left component Complex coefficients of the $1 / 2$ odd right component of the rectangular half wave" are shown in the row 42 of 
Table 2. The "Inverse Samples of the \{ Complex coefficients of the $1 / 2$ event left component - Complex coefficients of the $1 / 2$ odd right component of the rectangular half wave - Time Domain" are shown in the row 44 of Table 2. The "Complex coefficients of the \{ Complex coefficients of the $1 / 2$ event left component + Complex coefficients of the $1 / 2$ odd right component of the rectangular half wave $\}+\{$ Complex coefficients of the $1 / 2$ event left component -Complex coefficients of the $1 / 2$ odd right component of the rectangular half wave $\}$ " are shown in the row 46 of Table 2. The "Inverse Samples of the \{ Complex coefficients of the $1 / 2$ event left component + Complex coefficients of the $1 / 2$ odd right component of the rectangular half wave $\}+\{$ Complex coefficients of the $1 / 2$ event left component -Complex coefficients of the $1 / 2$ odd right component of the rectangular half wave $\}$ - Time Domain" are shown in the row 49 of Table 2. This final numerical result from simultaneous interpretation of Table 1 and Table 2 shows, that the inverse transformation using the relation (28) restore the initial "Rectangular Half Wave" signal in the row 49 of Table 2. This numerical proof of the first numerical example illustrates the statement, that the complex Fourier spectra has been calculated directly for the "Rectangular Half Wave" by MatLab program system [10] and complex Fourier spectra using the relation (28) restores accuracy of the initial time domain signal after inverse discrete Fourier transformation.

The study of complex numerical examples like "Rectangular Half Wave" is possible only with the help of computers, fast Fourier transformation and software systems such as MatLab [10].

The next eight numerical examples are specially selected. They are only symmetric or only anti symmetric. They can be detected and studied more easily, because the appropriate equivalent symmetric or anti symmetric functions can be evaluated directly from the MstLab Command Window.

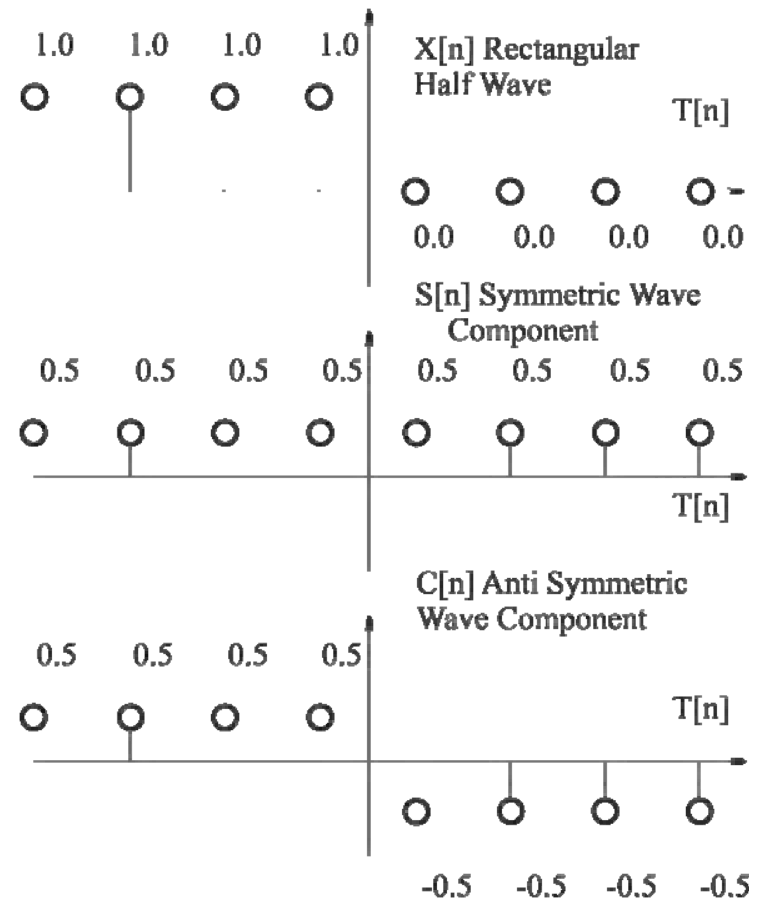

Fig. 3. Even - Odd Decomposition of the "Rectangular Half Wave"

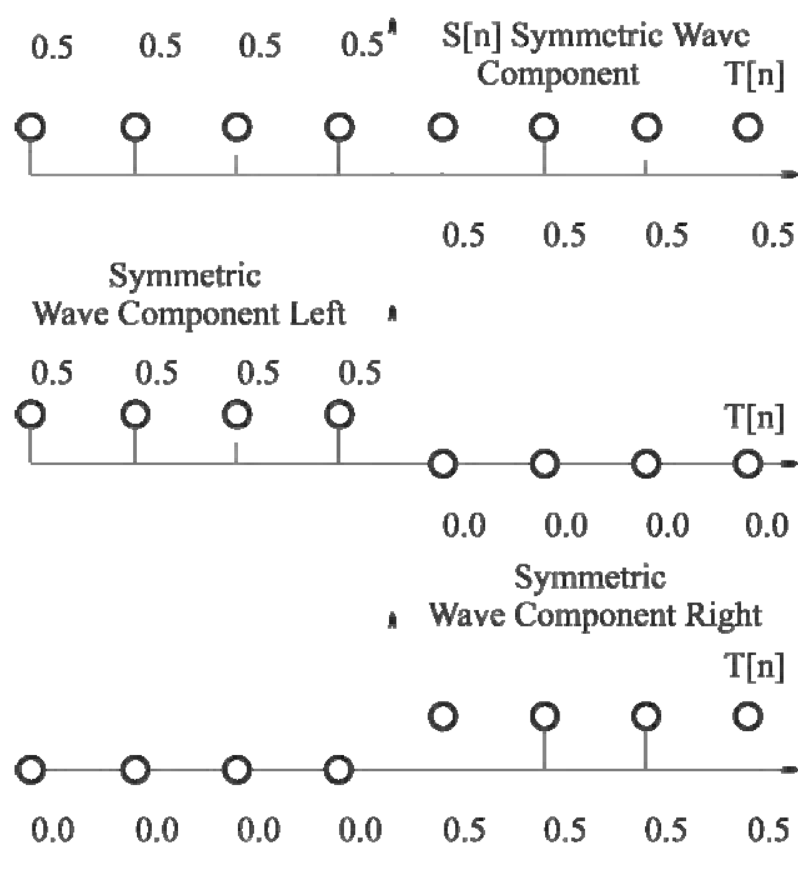

Fig. 4. Decomposition of the symmetric Wave Component to Symmetric Wave Component Left and Symmetric Wave Component Right, According to the relation (19) 


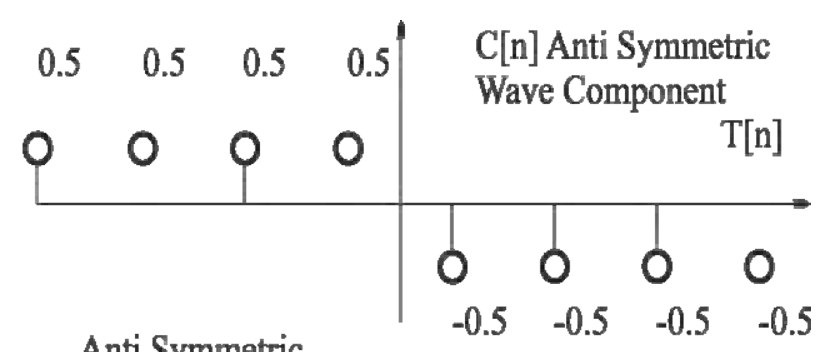

Anti Symmetric
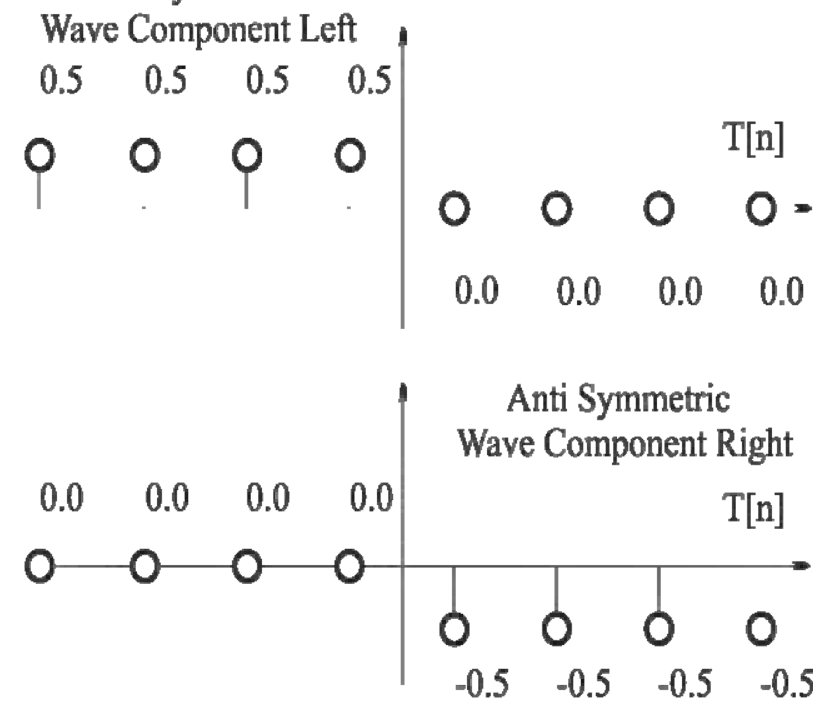

Fig. 5. Decomposition of the anti symmetric Wave Component to Anti Symmetric Wave Component Left and Anti Symmetric Wave Component Right, According to the relation (25) 


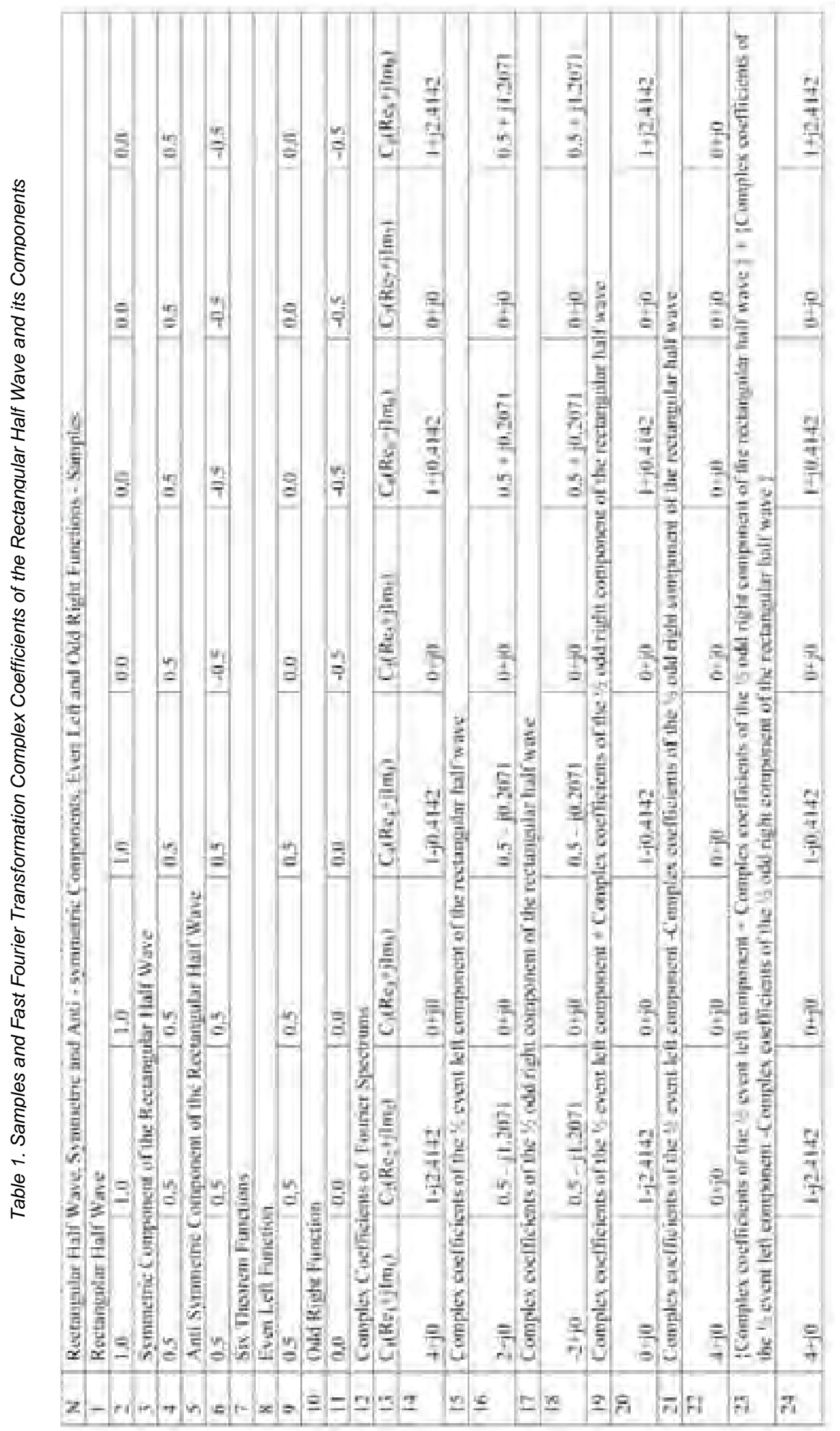




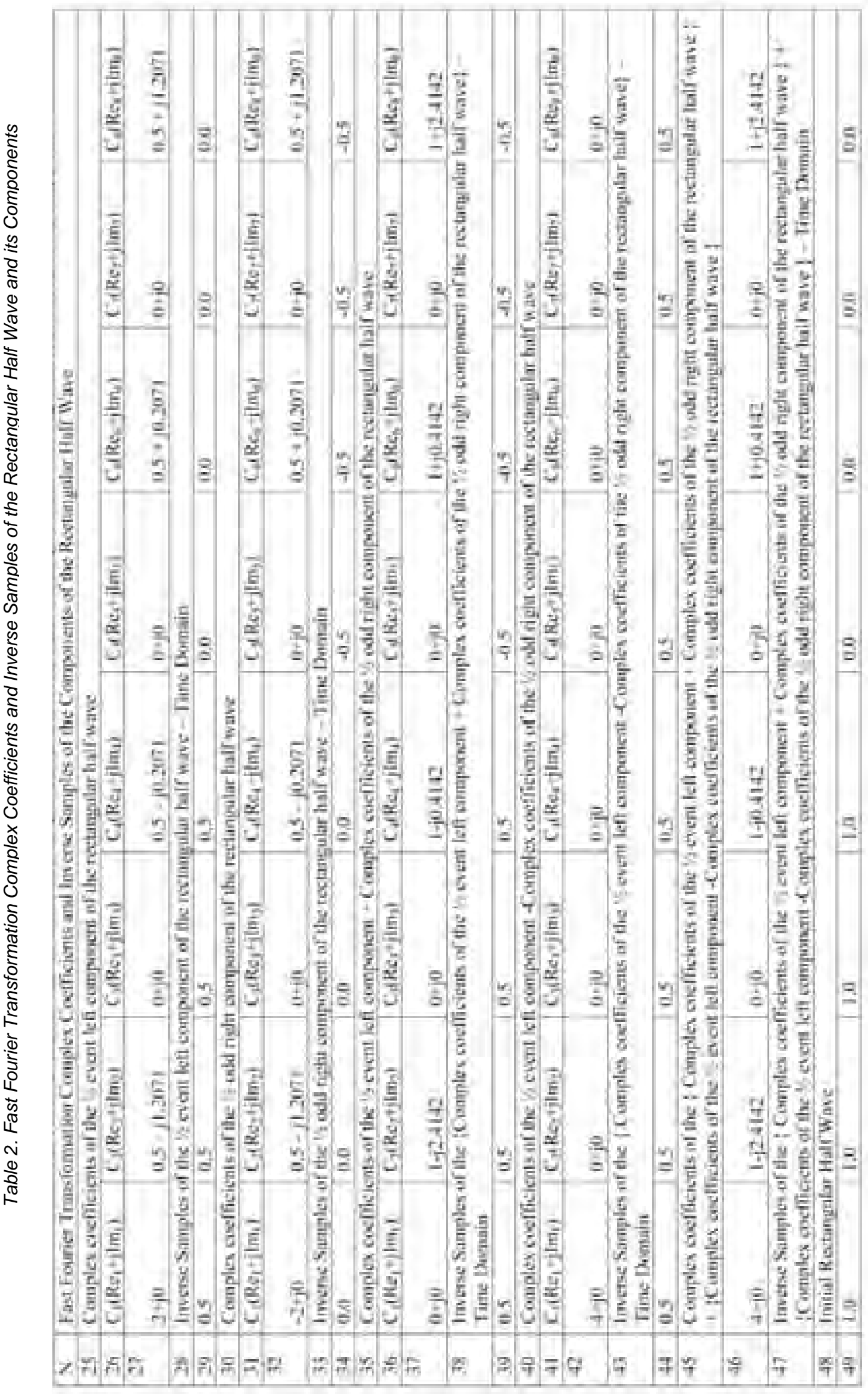


16 Samples Symmetric and Anti Symmetric Numerical Examples
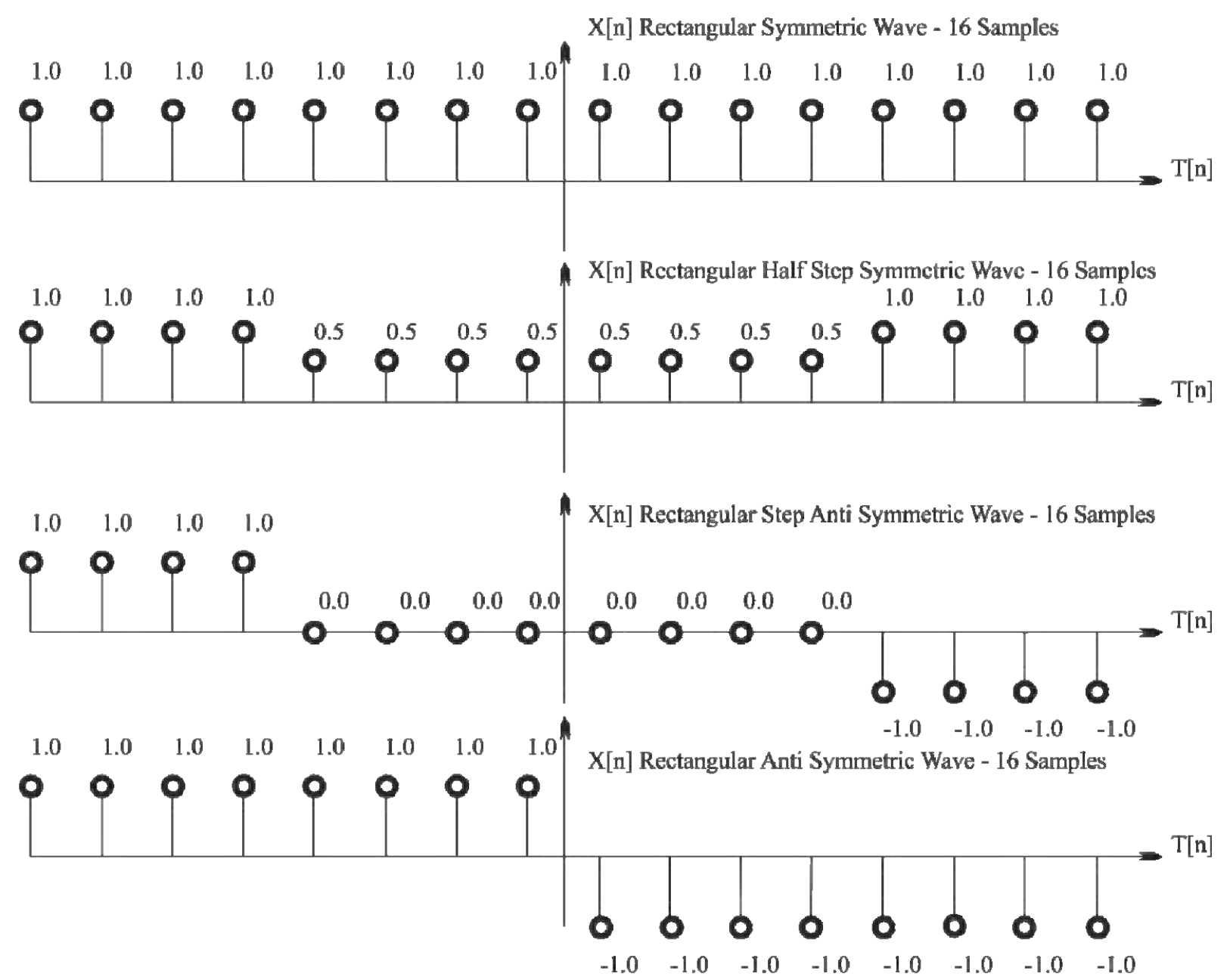

Fig. 6. Symmetric and Anti Symmetric Numerical examples, which illustrate the proof of the Theorem 6.

6.1) Full Rectangular Wave

6.2) Rectangular Half Step Symmetric Wave

6.3) Rectangular Step Anti Symmetric Wave

6.4) Rectangular Full Anti Symmetric wave

The Fourier complex spectra Y9 Octable Triangular Anti Symmetric Wave of the anti symmetric common function for this numerical example can be obtained by summarizing the Fourier complex spectra Y9 Octable
Triangular Anti Symmetric Wave Left and the Fourier complex spectra Y9 Octable Triangular Anti Symmetric Wave

Right. 


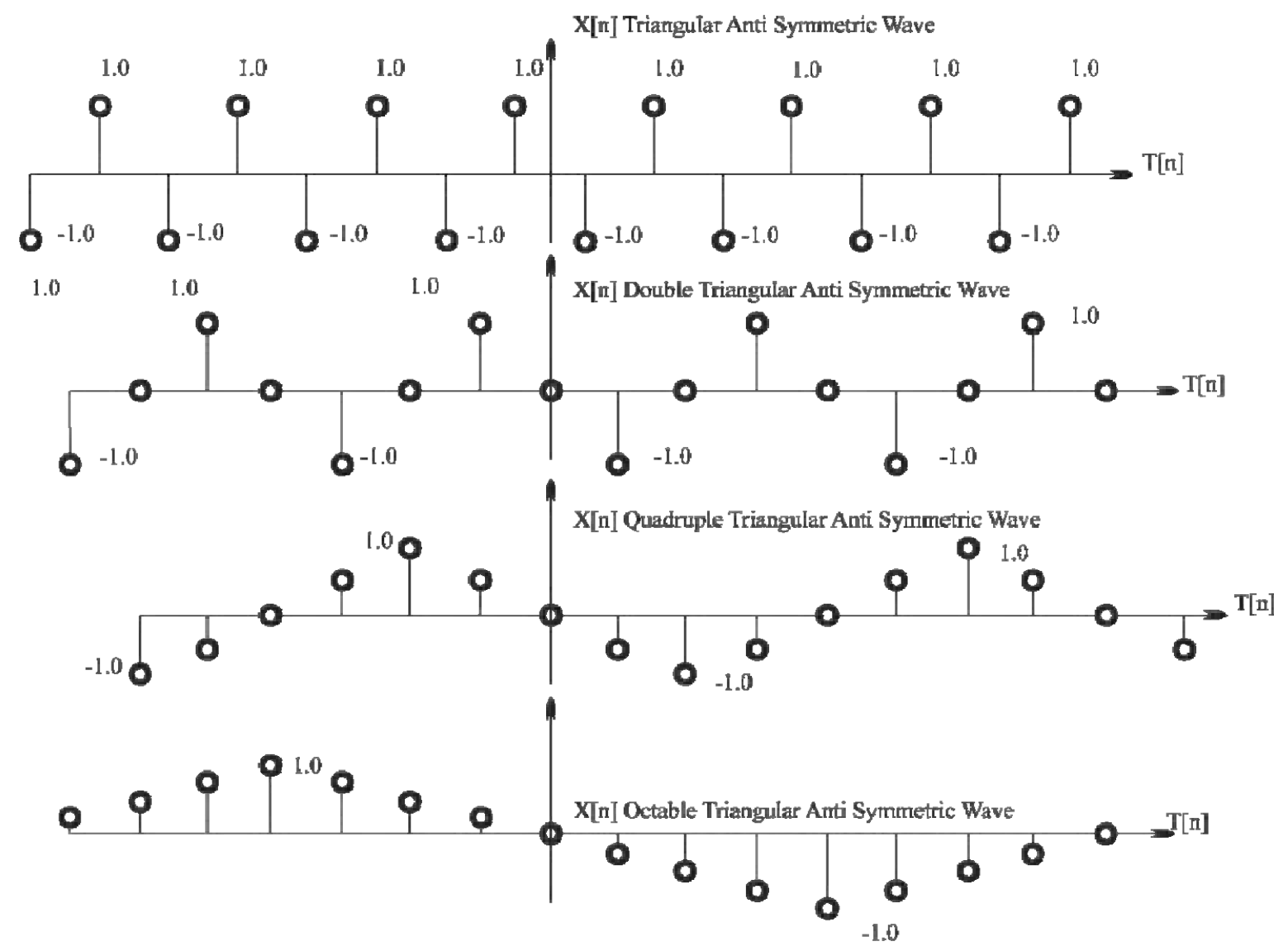

Fig. 7. Anti Symmetric Numerical examples, which illustrate the proof of the Theorem 6.

7.1) Triangular Anti Symmetric Wave

7.2) Double Triangular Anti Symmetric Wave

7.3) Quadruple Triangular Anti Symmetric Wave

7.4) Octable Triangular Anti Symmetric wave

\section{CONCLUSIONS}

The strategy of spectral even-odd decomposition of the arbitrary real function described in the paper allows constructing complex Fourier spectrum of initial signal with the length $\mathrm{N}$ in the time domain base on the

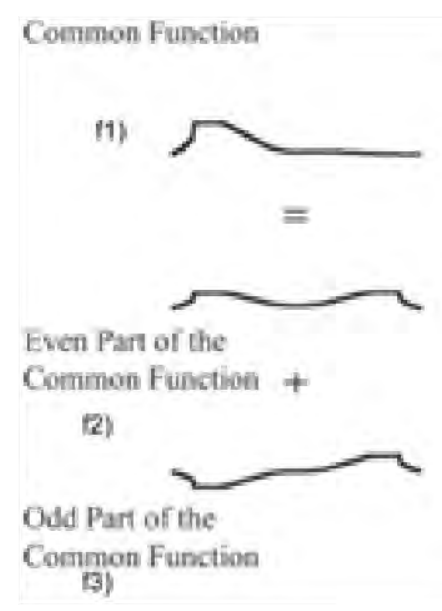

equivalent real and imaginary spectral parts with the length N/2 in the frequency domain. The Spectral EvenOdd Decomposition of Arbitrary Real Signals is shown in the figure 8.

\section{Even Part of the}

Commoe Function

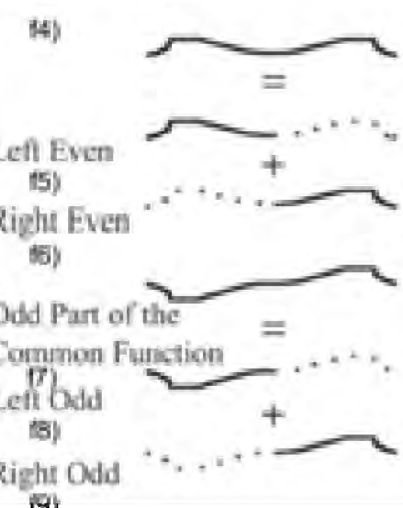

19)

Fig. 8. Spectral Even-Odd Decomposition of Arbitrary Real Signal f1. 
In the figure 8 the "black" line corresponds to nonzero values of the corresponding equivalent functions. The "points" line corresponds to zero values of the corresponding equivalent signals. On one hand the function f1 could be obtained by summarizing of functions $\mathrm{f} 2$ and $\mathrm{f} 3$ according to formulae (12). Function $\mathrm{f} 4 \mathrm{could}$ be obtained by summarizing of functions $\mathrm{f} 5$ and f6. Function $f 7$ could be obtained by summarizing of functions f8 and f9. Function f5 could be obtained by replacing the right side of the function $\mathrm{f} 4$ with zeros. Function $f 6$ could be obtained by replacing the left side of the function $\mathrm{f} 4$ with zeros. Function f8 could be obtained by replacing the right side of the function $f 7$ with zeros. Function f 9 could be obtained by replacing the left side of the function $\mathrm{f} 7$ with zeros. On the other hand the function $\mathrm{f} 1$ could be obtained by summarizing of the functions f5, f6, f8 and f9.

\section{REFERENCES}

[1] Philipoff Ph., N.Shopolov, K.Ishtev, P.Dineva, (1997), "Wave Propagation in Multilayered Media", Pergamon, Nonlinear Analysis, Theory, Methods \& Applications, Vol.30, No.4, pp. 2031-2040.

[2] Philipoff Ph., (2003), SH Wave Propagation trough Multilayer Media, Journal of Theoretical and Applied Mechanics N3, pp. 79-98.

[3] Philipoff Ph., Ph.Michaylov, (2007), "BELENE Nuclear Power Plant Numerical and Experimental Bedrock, Layers and Surface Signals", J. Applied Mathematical Modeling, 31 (2007), pp. 1889-1898, Elsevier.

[4] Philipoff Ph., Ph.Michaylov, (2007), "BELENE" Nuclear Power Plant Numerical and Experimental Free Field Signals, Siberian Journal Applied Mathematics, RAN - Siberian Branch Novosibirsk, (Сибирский журнал вычислительной математики, РАН, Сиб.отд-ние Новосибирск, том 10, N1, стр. 105-122), v.10, N1, pp. 105-122.

[5] Venelin Jivkov, Philip Philipoff, Anastas Ivanov, Mario Munoz, Galerida Raikova, Mikhail Tatur, Philip Michaylov, (2013), Spectral properties of quadruple symmetric real functions. Applied Mathematics and Computation 221 (2013) pp. 344-350

\section{ACKNOWLEDGEMENT}

The authors express their acknowledgment to "GPS Control" SA, "Aquapartner" Ltd and "Tokuda broker" Ltd for the financial support of this study.

[6] Alexander Poularikas, (2010), Transforms and Applications for Engineers with Examples and MATLAB, CRC Press is an imprint of Taylor \& Francis Group, an Informa business, International Standard Book Number-13: 978-1-4200-8932-5 (Ebook-PDF), statement $3.1 \mathrm{pp}-73$, statements 3.15 and 3.16 pp-75.

[7] Vasilev G., M. Ivanova, Z. Bonev, (2014), Long in plan buried structures subjected to seismic wave propagation, Mistal Service sas Via U. Bonino, 3, 98100 Messina (Italy), ISBN: 978-88-98161-05-8

[8] Meirovitch Leonard, (1986), Elements of Vibration Analysis, Mc Graw-Hill Book Company, 1986, pp 559.

[9] Smirnoff, V.I., (1974), Course of Higher Mathematics, v.1, "Nauka", Moscow, 1974, pp 225, (in Russian).

[10] MATLAB <http://www.mathworks.com/products/matlab/>, 2010. 


\section{QUADRUPLE SYMMETRIC REAL SIGNALS SPECTRAL EVEN AND ODD DECOMPOSITION}

Venelin JIVKOV

Philip PHILIPOFF

The spectral properties of quadruple symmetric real signals are analyzed in the study. Six number theorems are formulated and proofed analytically in a capacity of central results of the research. Lasted theorem could be used to construct complex Fourier spectrum for arbitrary real function by even - odd decomposition. The theorem is illustrated numerically. The initial signal with length $\mathrm{N}$ (analogous values length interval or number of discrete samples) in the time domain is Fourier transformed through two spectral - real and imaginary parts with length $\mathrm{N}$ in the frequency domain. The real and imaginary parts of the complex Fourier spectrum of the initial signal, could be obtained by procedure, described in the paper. Spectral parts could be calculated by equivalent functions-signals. Even left and odd right equivalent functions-signals contain $\mathrm{N} / 2$ nonzero analogous values or discrete samples. This strategy allows constructing complex Fourier spectrum of the initial signal with length $\mathrm{N}$ in the time domain based on equivalent real and imaginary spectral parts with the length $N / 2$ in the frequency domain. The study is an extension and resumé of AMC 221(2013) pp. 344-350.

Key words: Quadruple symmetric real signals, Symmetry - Conjugation relation, Spectral even-odd decomposition

\section{SPEKTRALNA DEKOMPOZICIJA ČETVOROSTRUKO SIMETRIČNIH REALNIH SIGNALA PARNIM I NEPARNIM DELOVIMA SIGNALA}

Venelin JIVKOV

Philip PHILIPOFF

$\mathrm{U}$ ovom radu su analizirane spektralne karakteristike četvorostruko simetričnih realnih signala. Analitički je formulisano i testirano šest teorema kao centralni rezultat istraživanja. Poslednja (šesta) teorema se može koristiti za proračun Fourier-ovog spektra proizvoljne realne funkcije dekompozicijom parnim i neparnim delovima signala. Teorema je ilustrovana numerički. Transformacija inicijalnog signala dužine $N$ (broj diskretnih vrednosti) iz vremenskog domena u frekventan domen je sprovedena Fourier-ovim transformacijama kroz dva spektralna realna i imaginarna dela dužine $N$. Realni i imaginarni deo kompleksnog Fourier-ovog spektra inicijalnog signala može se proračunati primenom ekvivalentnih funkcija (signala). Leve parne i desne neparne ekvivalentne funkcije (signali) sadrže N/2 nenulte analogne vrednosti ili diskretne uzorke. Ova strategija omogućava izgradnju kompleksnog Fourier-ovog spektra, inicijalnog signala dužine $N$ u vremenskom domenu, ekvivalentnim realnim i imaginarnim spektralnim delovima dužine N/2 u frekventnom domenu. Studija bi mogla da se posmatra kao nastavak i rezime istraživanja (Jivkov et all, 2013).

Ključne reči: četvorostruko simetrični realni signal, relacija (odnos) simetrija - konjugacija, spektralna dekompozicija parnim i neparnim delovima signala 